Check for updates

Cite this: Chem. Sci., 2019, 10, 3592

๑ All publication charges for this article have been paid for by the Royal Society of Chemistry

Received 11th September 2018

Accepted 12th February 2019

DOI: $10.1039 / \mathrm{c} 8 \mathrm{sc} 04044 \mathrm{c}$

rsc.li/chemical-science

\section{Flux melting of metal-organic frameworks $\dagger$}

\author{
Louis Longley, ${ }^{a}$ Sean M. Collins, (D) a Shichun Li, ${ }^{\text {ab }}$ Glen J. Smales, ${ }^{\text {cd }}$ Ilknur Erucar, (D) e \\ Ang Qiao, ${ }^{f}$ Jingwei Hou, (DD ${ }^{a}$ Cara M. Doherty, (D) ${ }^{g}$ Aaron W. Thornton, ${ }^{g}$ \\ Anita J. Hill, (D) ${ }^{g}$ Xiao Yu, ${ }^{\text {h }}$ Nicholas J. Terrill, (D) ${ }^{d}$ Andrew J. Smith, (D) ${ }^{d}$ \\ Seth M. Cohen, (D) ${ }^{\mathrm{h}}$ Paul A. Midgley, ${ }^{a}$ David A. Keen, (D) Shane G. Telfer $\mathbb{( D D}^{\mathrm{j}}$ \\ and Thomas D. Bennett (D) *a
}

\begin{abstract}
Recent demonstrations of melting in the metal-organic framework (MOF) family have created interest in the interfacial domain between inorganic glasses and amorphous organic polymers. The chemical and physical behaviour of porous hybrid liquids and glasses is of particular interest, though opportunities are limited by the inaccessible melting temperatures of many MOFs. Here, we show that the processing technique of flux melting, 'borrowed' from the inorganic domain, may be applied in order to melt ZIF-8, a material which does not possess an accessible liquid state in the pure form. Effectively, we employ the high-temperature liquid state of one MOF as a solvent for a secondary, non-melting MOF component. Differential scanning calorimetry, small- and wide-angle X-ray scattering, electron microscopy and X-ray total scattering techniques are used to show the flux melting of the crystalline component within the liquid. Gas adsorption and positron annihilation lifetime spectroscopy measurements show that this results in enhanced, accessible porosity to a range of guest molecules in the resultant flux melted MOF glass.
\end{abstract}

\section{Introduction}

Porous three dimensional materials formed by the self-assembly of inorganic nodes connected by organic ligands or, as they are commonly known, metal-organic frameworks (MOFs), ${ }^{1}$ remain of extreme interest to the scientific community. The continuation of new materials discovery, combined with an improved understanding of the relationship between structure, property and

${ }^{a}$ Department of Materials Science and Metallurgy, University of Cambridge, Charles Babbage Road, Cambridge, CB3 OFS, UK. E-mail: tdb35@cam.ac.uk

${ }^{b}$ Institute of Chemical Materials, China Academy of Engineering Physics, Mianyang 621900, China

'Department of Chemistry, University College London, Gordon Street, London, WC1H OAJ, UK

${ }^{d}$ Diamond Light Source Ltd, Diamond House, Harwell Science and Innovation Campus, Didcot OX11 ODE, UK

${ }^{e}$ Department of Natural and Mathematical Sciences, Faculty of Engineering, Ozyegin University, Istanbul, Turkey

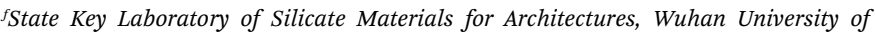
Technology, Wuhan 430070, China

${ }^{g}$ Future Industries, Commonwealth Scientific and Industrial Research Organisation, Clayton South, Victoria 3168, Australia

${ }^{h}$ Department of Chemistry and Biochemistry, University of California, San Diego, La Jolla, California 92023-0358, USA

${ }^{i}$ ISIS Facility, Rutherford Appleton Laboratory, Harwell Campus, Didcot, Oxon OX11 $O Q X, U K$

${ }^{j}$ MacDiarmid Institute for Advanced Materials and Nanotechnology, Institute of Fundamental Sciences, Massey University, Palmerston North 4442, New Zealand

$\dagger$ Electronic supplementary information (ESI) available. See DOI: $10.1039 / \mathrm{c} 8 \mathrm{sc} 04044 \mathrm{c}$ application, drives intense research into their use in carbon capture, clean water production, catalysis, drug delivery, and light harvesting. ${ }^{2,3}$ Their thermomechanical properties have also generated a surge of recent studies, revolving around flexibility, ${ }^{4}$ negative gas adsorption, ${ }^{5}$ and defect-dependent properties. ${ }^{6}$ Rapid developments have also been made in asserting control over macroscale MOF architectures, ${ }^{7}$ such as membranes, ${ }^{\mathbf{8}}$ monoliths, ${ }^{9}$ and thin films. ${ }^{10}$ Although many MOFs can be processed into pellet forms, their mechanical instabilities are not conducive to processing of their nano-crystalline structures into bulk structures which are free from grain boundaries. ${ }^{\mathbf{1 1}}$ Set against this backdrop, there remains a necessity for MOFs in macroscale architectures that retain porous properties, but circumvent the drawbacks associated with processing and handling microcrystalline powders.

Zeolitic imidazolate frameworks (ZIFs) are a subset of MOFs in which tetrahedral metal centers are connected by imidazolate (Im, $\mathrm{C}_{3} \mathrm{H}_{3} \mathrm{~N}_{2}{ }^{-}$) based ligands. ${ }^{12,13}$ Amongst these, the prototypical framework ZIF-8, $\mathrm{Zn}(\mathrm{mIm})_{2}$ (mIm, 2-methylimidazolate, $\mathrm{C}_{4} \mathrm{H}_{5} \mathrm{~N}_{2}{ }^{-}$), is investigated extensively. ${ }^{\mathbf{1 4 , 1 5}}$ For example, the structure, which contains pores of diameter $11.6 \AA$, has been shown to exhibit selectivity for the removal of $\mathrm{Li}^{+}$ions from water, courtesy of the $3.4 \AA$ limiting pore window size. ${ }^{16}$ The formation of mixed-matrix membranes (MMMs) through dispersal of ZIF-8 within an organic polymer has also been attempted, ${ }^{17}$ though products may suffer from poor adhesion between the two components. Cross-linking of the ZIF to the organic matrix, through either amine surface functionalization of the ZIF, or from high-temperature heat treatment of the MMM, have been 
investigated as potential solutions to the problem of chemical compatibility between the two components. ${ }^{18,19}$

Recently, several members of the ZIF family have been observed to melt upon heating to temperatures above $673 \mathrm{~K}^{20}$ Cooling the liquid ZIF below these temperatures potentially allows the ZIF to be shaped and handled akin to a conventional silicate glass. However, the temperature window over which these materials remain intact in their liquid state is bounded by the temperature of thermal decomposition $\left(T_{\mathrm{d}}\right),{ }^{21}$ which is up to $c a$. $100 \mathrm{~K}$ higher than the melting temperature $\left(T_{\mathrm{m}}\right)$. The $\left[\mathrm{Zn}(\mathrm{Im})_{2}\right]$ glasses produced upon cooling from the liquid state possess continuous random networks, mimicking that of amorphous $\mathrm{SiO}_{2}$. The dominant $\mathrm{Zn}-\mathrm{N}$ coordination bonding in the glass state means that they form a new, $4^{\text {th }}$ category of melt-quenched glasses, distinct from the inorganic (non-metallic), organic and metallic glass categories known at present. ${ }^{22}$ The melting behaviour of ZIFs, alongside that of phosphate-based porous coordination polymers, ${ }^{23,24}$ therefore opens up unexplored avenues in the synthesis and processing of new MOF-based glasses. ${ }^{25}$

The melting process in metal-imidazolate and -phosphate coordination polymer/metal-organic framework families has been observed to obey Lindemann's law, ${ }^{20,24,26}$ in which the ratio of the mean thermal atomic displacement of a species, and the distance to the nearest neighbour, approaches $0.1-0.13$ at the melting temperature. A microscopic structural view of ZIF melting, obtained by molecular dynamics simulation, shows that $\mathrm{Zn}-\mathrm{Im}$ bond breaking is a rare event. This rare event is followed by movement of the Im ligand away from the now under coordinated $\mathrm{Zn}^{2+}$ center, before association of a different imidazolate. This melting process, which has been likened to hydrogen bond switching in water, ${ }^{20}$ has only been observed in ZIFs containing the Im species. Other materials, including ZIF8 , do not melt $^{27}$ and this places severe constrictions on the chemical and network functionality of the resultant glasses. Pathways are therefore being sought to reduce the $T_{\mathrm{m}}$ of nonmelting ZIF structures below $T_{\mathrm{d}}$.

In the molten salt domain, the problem of reducing $T_{\mathrm{m}}$ is approached through use of a flux. For example, $\mathrm{Na}_{2} \mathrm{O}\left(T_{\mathrm{m}} \approx 1400\right.$ $\mathrm{K})$ is used to lower the melting temperature of $\mathrm{SiO}_{2}\left(T_{\mathrm{m}} \approx 2000\right.$ $\mathrm{K}),{ }^{28}$ whilst in addition molten oxide fluxes enable production of bulk metallic glasses. ${ }^{29}$ Organic analogies also exist, in the use of ionic liquids as solvents for secondary species. ${ }^{30,31}$ Encouraged by the similarities between inorganic glasses and those formed by melting ZIFs, we hypothesized that the high-temperature liquid state of a ZIF may serve as a flux - that is, a solvent - for other ZIFs. This strategy is successfully used to form a glass, derived from a high-temperature liquid of ZIF-62 $\left[\mathrm{Zn}\left(\mathrm{C}_{3} \mathrm{H}_{3} \mathrm{~N}_{2}\right)_{1.75^{-}}\right.$ $\left.\left(\mathrm{C}_{7} \mathrm{H}_{5} \mathrm{~N}_{2}\right)_{0.25}\right]\left(\mathrm{bIm}=\right.$ benzimidazolate, $\left.\mathrm{C}_{7} \mathrm{H}_{5} \mathrm{~N}_{2}{ }^{-}\right)$and ZIF-8. The resultant flux melted glass displays increased porosity towards $\mathrm{H}_{2}$, compared with the pure MOF-glass.

\section{Experimental}

\section{Synthesis}

The synthesis of ZIF-62 was taken from Gustafsson et al. ${ }^{32}$ Specifically, solutions in DMF of $\mathrm{Zn}\left(\mathrm{NO}_{3}\right)_{2} \cdot 6 \mathrm{H}_{2} \mathrm{O}(0.2 \mathrm{M})$, imidazole $(1.5 \mathrm{M})$ and benzimidazole $(0.2 \mathrm{M})$ were prepared, and mixed together in the ratio $\mathrm{Zn}: \mathrm{Im}: \mathrm{bIm}$ of $1: 13.5: 1.5$. Solutions were heated at $403 \mathrm{~K}$ for 96 hours and cooled to ambient temperature. The microcrystalline product was washed three times in DMF, and dried at $373 \mathrm{~K}$ for 4 hours. ZIF-8 was purchased from Sigma Aldrich and used as received. A reported, steam-assisted synthesis was used for ZIF-67. ${ }^{33}$

The preparation of mixed samples was carried out in $0.5 \mathrm{~g}$ quantities. For example, 0.1 and $0.4 \mathrm{~g}$ of ZIF- 8 and ZIF-62 were placed in a $10 \mathrm{~mL}$ stainless steel jar, along with $2 \times 7 \mathrm{~mm}$ stainless steel balls. The mixture was then milled for 5 minutes (for Zn based samples) or 15 minutes (for Co based samples) in a Retsch MM400 grinder mill operating at $25 \mathrm{~Hz}$ (Fig. S1†). The different milling times were to accommodate the different initial particle sizes of ZIF-8, and ZIF-67 (Fig. S2 $\dagger$ ), given the larger initial particle sizes of the as-synthesized ZIF-67 phase. These crystalline mixtures were subsequently heated to $453 \mathrm{~K}$ for 3 hours to remove the solvent.

To form the glasses, $0.25 \mathrm{~g}$ of the evacuated crystalline mixture was placed in a ceramic crucible in a tube furnace, which was sealed and flushed with argon for 30 minutes. ZIF-8/ ZIF-62 and ZIF-67/ZIF-62 mixtures were then heated at 10 $\mathrm{K} \mathrm{min}{ }^{-1}$ to the temperatures indicated in the main text. This was followed by natural cooling back to room temperature, still under flowing argon.

\section{Characterization}

Differential scanning calorimetry. Experiments were conducted using a Netzsch STA 449 F1 instrument, in sealed platinum crucibles at a $10 \mathrm{~K} \mathrm{~min}^{-1}$ heating rate. To determine the $C_{\mathrm{p}}$ of the samples, both the baseline (blank) and the reference sample (sapphire) were measured. Simultaneous differential scanning calorimetry-thermogravimetric analyses were performed using a TA instruments Q-600 series differential scanning calorimeter, with the sample ( $c a .7 \mathrm{mg}$ ) held in an alumina pan under a continuous flow of dry Ar gas. The data were obtained using a heating rate of $10 \mathrm{~K} \mathrm{~min}^{-1}$. Downscans were also conducted at $10 \mathrm{~K} \mathrm{~min}^{-1}$.

X-ray scattering. Powder diffraction data were collected with

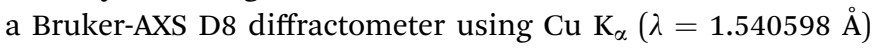
radiation and a LynxEye position sensitive detector in BraggBrentano parafocusing geometry.

Combined small and wide angle X-ray scattering data were collected at the I22 beamline at the Diamond Light Source, UK $(\lambda=0.9998 \AA, 12.401 \mathrm{keV})$. The SAXS detector was positioned at a distance of $9.23634 \mathrm{~m}$ from the sample as calibrated using a $100 \mathrm{~nm}$ period $\mathrm{Si}_{3} \mathrm{~N}_{4}$ grating (Silson, UK), giving a usable $q$ range of $0.0018-0.18 \AA^{-1}$. The WAXS detector was positioned at a distance of $0.16474 \mathrm{~m}$ from the sample as calibrated using a standard $\mathrm{CeO}_{2}$ sample (NIST SRM 674b, Gaithersburg USA), giving a usable $q$ range of $0.17-4.9 \AA^{-1}$. Samples were loaded into $1.5 \mathrm{~mm}$ diameter borosilicate capillaries under argon inside a glovebox and sealed with Blu-tack and Para-film to prevent the ingress of air. Samples were heated using a Linkam THMS600 capillary stage (Linkam Scientific, UK) from room temperature to $873 \mathrm{~K}$ at $10 \mathrm{~K} \mathrm{~min}^{-1}$. Simultaneous SAXS/WAXS data were collected every $1 \mathrm{~K}$. Data were reduced to $1 \mathrm{D}$ using the 
DAWN package ${ }^{34,35}$ and standard reduction pipelines. ${ }^{36}$ Values for the power law behavior of the samples were found using the power law model of SASView 4.1.1. ${ }^{37}$ Data were fitted over the range $0.003 \leq q \leq 0.005 \AA^{-1}$. Particle size distributions were calculated using the McSAS package ${ }^{38,39}$ a minimal assumption Monte Carlo method for extracting size distributions from small-angle scattering data. Data were fitted over a range of $0.002 \leq q \leq 0.18 \AA^{-1}$ with a sphere model.

$\mathrm{X}$-ray total scattering data were collected at room temperature using a PANalytical Ag-source Empyrean lab diffractometer $(\lambda=0.561 \AA)$. Data collection was carried out using loaded $1.0 \mathrm{~mm}$ diameter quartz capillaries and collection times of approximately 6 h. Background, multiple scattering, container scattering, Compton scattering and absorption corrections were performed using the GudrunX program. ${ }^{\mathbf{4 0 , 4 1}}$

Nuclear magnetic resonance spectroscopy. Solution ${ }^{1} \mathrm{H}$ NMR spectra of digested samples (in a mixture of $\mathrm{DCl}(35 \%) / \mathrm{D}_{2} \mathrm{O}(0.1$ $\mathrm{mL}$ ) and $\mathrm{DMSO}_{6}(0.5 \mathrm{~mL})$ ) of samples (about $6 \mathrm{mg}$ ) were recorded on a Bruker Avance III $400 \mathrm{MHz}$ spectrometer at $293 \mathrm{~K}$. Chemical shifts were referenced to the residual protio-solvent signals of DMSO- $\mathrm{d}_{6}$. The spectra were processed with the MestreNova Suite.

Electron microscopy and spectroscopy. Scanning transmission electron microscopy data were acquired using an FEI Osiris microscope equipped with a high-brightness X-FEG electron source and operated at $80 \mathrm{kV}$. The beam convergence was set to 11.0 mrad. X-ray energy dispersive spectroscopy (EDS) was acquired using a 'Super-X' EDS detector system with four detectors mounted symmetrically about the optic axis of the microscope (200 ms per pixel). For all spectroscopic data, images were also simultaneously recorded on annular dark field (ADF) detectors. These images contain atomic number and thickness contrast, giving information in parallel with the mapping obtained in the EDS data. Data were processed using Hyperspy, ${ }^{42}$ an open-source software coded in Python. EDS maps were generated by peak integration at the $\mathrm{K}_{\alpha} \mathrm{X}$-ray emission line for each element.

Simulations. Full details are available in the ESI. $\dagger$

Positron annihilation lifetime spectroscopy. ${ }^{22} \mathrm{NaCl}$, which was sealed in a thin Mylar envelope, was used as the source of positrons. The samples were packed to $2 \mathrm{~mm}$ thickness surrounding the positron source. The $o$-Ps lifetime measurements were taken under vacuum $\left(1 \times 10^{-5}\right.$ Torr $)$ at $298 \mathrm{~K} \mathrm{using}$ an EG\&G Ortec spectrometer at a rate of $4.5 \times 10^{6}$ counts per sample. The spectra were fitted to 4 lifetime components with the first two components accounting for $p$-Ps and free annihilation respectively. The $3 \mathrm{rd}$ and 4 th component lifetimes $\left(\tau_{3}\right.$ and $\tau_{4}$ ) were related to $o$-Ps annihilation and are correlated to the average pore sizes within the materials. The lifetimes were converted to pore sizes by using the Tao-Eldrup quantum-based formulation with a spherical pore geometry. ${ }^{43} \mathrm{~A}$ full description of the technique can be found in a previous study. ${ }^{\mathbf{4 4}}$

Gas adsorption. Gas adsorption isotherms were measured by a volumetric method using ultra-high purity gases. Prior to analysis, the samples were degassed under a dynamic vacuum at $10^{-6}$ Torr for $10-20$ hours at $130-250{ }^{\circ} \mathrm{C}$. Accurate sample masses were calculated using degassed samples after sample tubes were backfilled with nitrogen. Where possible, BET surface areas were calculated from adsorption isotherms according to established procedures. ${ }^{45}$

\section{Results and discussion}

\section{Thermal characterization of flux melting}

Selection of the two components was based upon the requirement for an accessible and reasonably wide temperature region over which the liquid, and crystalline MOFs, were both stable. That is, the two components should obey the condition $T_{\mathrm{m} 1}<$ $T_{\mathrm{d} 2}$, where $T_{\mathrm{m} 1}$ refers to the melting temperature of structure 1, the liquid-forming $\mathrm{MOF}$, and $T_{\mathrm{d} 2}$ to the decomposition temperature, or upper stability limit, of the crystalline form of component 2. A suitable combination was found (Fig. 1a) using: (i) the comparatively low $T_{\mathrm{m}}$ of $\mathrm{ca} .710 \mathrm{~K}$ established for ZIF-62 $\left[\mathrm{Zn}\left(\mathrm{C}_{3} \mathrm{H}_{3} \mathrm{~N}_{2}\right)_{1.75}\left(\mathrm{C}_{7} \mathrm{H}_{5} \mathrm{~N}_{2}\right)_{0.25}\right],{ }^{46}$ and (ii) the relatively high $T_{\mathrm{d}}$ of ZIF-8 (ca. $800 \mathrm{~K}$ at a heating rate of $\left.10 \mathrm{~K} \mathrm{~min}^{-1}\right) .{ }^{21}$

ZIF-62 was synthesized according to literature procedures, and combined with a sample of commercially purchased ZIF-8. Specifically, the two microcrystalline samples were mixed together in a 20/80 (ZIF-8/ZIF-62) wt/wt ratio, and ball-milled for 5 minutes to homogenize the sample. The sample was then evacuated by heating at $453 \mathrm{~K}$ for 3 hours. This evacuation of solvent did not result in a change in crystal structure (Fig. S1 and $\mathrm{S} 2 \dagger)$. The resultant mix of crystalline frameworks is hereby referred to as (ZIF-8)(ZIF-62)(20/80). Differential scanning a

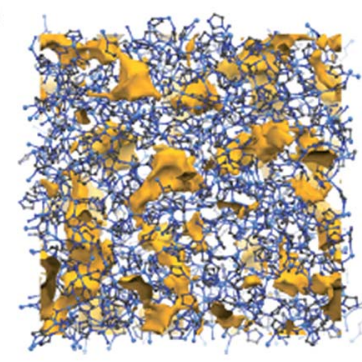

Liquid ZIF

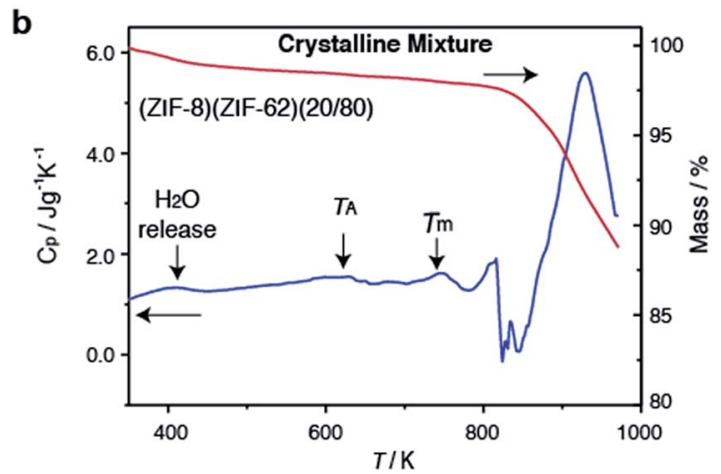

Fig. 1 (a) Atomic configuration, ca. $50 \AA^{3}$, of a high-temperature liquid ZIF obtained from a previous publication through computational, and experimental neutron and synchrotron pair distribution function modelling. ${ }^{20}$ Also included is the unit cell of ZIF- $8 .{ }^{12} \mathrm{Zn}$ - light blue, $\mathrm{N}$ dark blue, C - grey, $\mathrm{H}$ - omitted for clarity. Void space - yellow. (b) Isobaric heat capacity $\left(C_{p}\right)$ and mass as a function of temperature for (ZIF-8)(ZIF-62)(20/80), at a heating rate of $10 \mathrm{~K} \mathrm{~min}^{-1}$. 
calorimetry (DSC) experiments were performed up to $973 \mathrm{~K}$ in an inert argon atmosphere (Fig. 1b). A broad endotherm at $c a$. $600 \mathrm{~K}$ indicative of thermal amorphisation, followed by an endothermic melting peak at $c a .730 \mathrm{~K}$ was observed, broadly consistent with prior observations. ${ }^{46}$

In a separate, simultaneous differential scanning calorimetrythermogravimetric (SDT) experiment, (ZIF-8)(ZIF-62)(20/80) was heated to $773 \mathrm{~K}$ at a rate of $10 \mathrm{~K} \mathrm{~min}^{-1}$, i.e. above the melting temperature of ZIF-62, and then quenched at a rate of $10 \mathrm{~K} \mathrm{~min}^{-1}$ back to room temperature. This produced a solid, self-supporting monolith, hereby referred to as $\mathrm{a}_{\mathrm{g}}\left[(\mathrm{ZIF}-8)_{0.2}(\mathrm{ZIF}-62)_{0.8}\right]$, of strikingly different external appearance to the microcrystalline mixture prior to heating (Fig. 2a inset). This terminology differentiates the flux melted glasses, from metal-organic framework blends, e.g. (ZIF-4) $)_{0.5}(\mathrm{ZIF}-62)_{0.5},{ }^{47}$ in which both constituent amorphous MOF component structures appear to remain intact. Scanning electron microscopy (Fig. $2 \mathrm{~b}$ and $\mathrm{S} 2 \dagger$ ) demonstrated that the individual particles coalesce upon their transformation into $\mathrm{a}_{\mathrm{g}}\left[(\mathrm{ZIF}-8)_{0.2}(\mathrm{ZIF}-62)_{0.8}\right]$, with no distinct, remnant particles from either ZIF-8 or ZIF-62 observable in this material. Consistent with these observations, the powder X-ray diffraction (PXRD) pattern of $a_{g}\left[(Z I F-8)_{0.2}(Z I F-62)_{0.8}\right]$ contained no Bragg scattering (Fig. 2a). A sample of pure ZIF-8 was also ball-milled for 5 minutes and heated to $773 \mathrm{~K}$, then subsequently cooled to room temperature (Fig. S3†). Crystallinity was shown to remain intact.

The glassy nature of $a_{g}\left[(Z I F-8)_{0.2}(Z I F-62)_{0.8}\right]$ was confirmed by a second DSC heating curve (Fig. S4†), which demonstrated

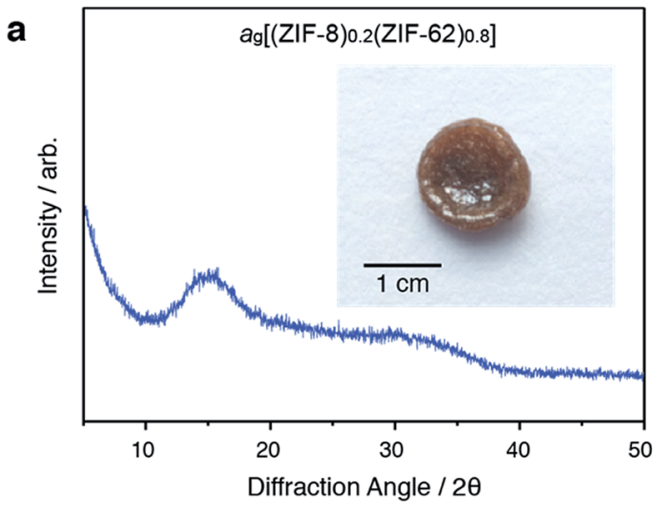

b

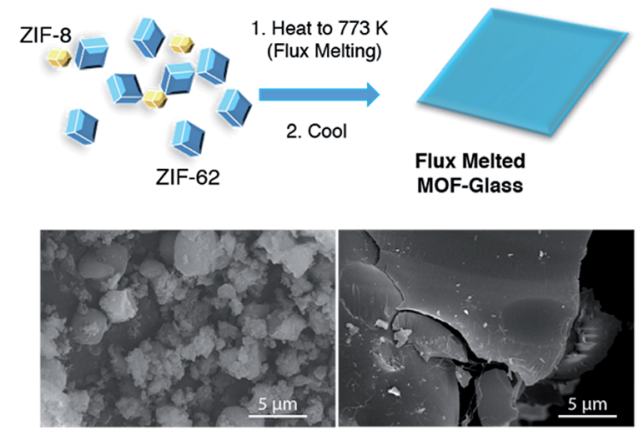

Fig. 2 (a) Powder X-ray diffraction pattern of the glass formed after quenching from $773 \mathrm{~K}$, and (inset) optical image. (b) Schematic of flux melted glass formation and SEM images of (left) (ZIF-8)(ZIF-62)(20/80) and (right) $a_{g}\left[(Z I F-8)_{0.2}(Z I F-62)_{0.8}\right]$.

a glass transition of $T_{\mathrm{g}}=607 \mathrm{~K}$. This value is greater than that for pure ZIF-62 $\left(T_{\mathrm{g}}=591 \mathrm{~K}\right) .{ }^{46}$ Thermogravimetric analysis (TGA) on the sample indicated that no mass was lost on heating to $c a .850 \mathrm{~K}$ (Fig. S5 $\dagger$ ). ${ }^{1} \mathrm{H}$ nuclear magnetic resonance (NMR) spectroscopy on digested samples of $\mathrm{a}_{\mathrm{g}}\left[(\mathrm{ZIF}-8)_{0.2}(\mathrm{ZIF}-62)_{0.8}\right]$ confirmed the presence of the Im, mIm, and bIm linkers (Fig. S6†).

\section{Structural evolution during flux melting}

To further investigate the structural changes upon melting, in situ wide-angle X-ray scattering (WAXS) data were collected on a sample of (ZIF-8)(ZIF-62)(20/80) at the Diamond Light Source. As in prior studies, where the technique has proven useful in elucidating the mechanisms of MOF particle growth in solution, ${ }^{\mathbf{4 8}}$ the WAXS data were combined with simultaneously collected small-angle X-ray scattering (SAXS) data. Amorphization of ZIF-62, indicated by the disappearance of the (211) peak in the temperature resolved WAXS profile, takes place at ca. 600 $\mathrm{K}$ (Fig. 3a), consistent with previous observations and the DSC trace (Fig. 1). ${ }^{46}$ The remaining Bragg diffraction from ZIF-8, for example the (110) peak, then disappears by ca. $650 \mathrm{~K}$.

Porod fitting of the variable temperature SAXS profile (Fig. S7 and $\mathrm{S} 8 \dagger$ ) at room temperature, reveals that the decay in SAXS signal follows power law behavior of the form $q^{-\alpha}$, where $\alpha=$ 3.65. This remains constant to $c a .573 \mathrm{~K}$, before dropping to $\alpha=$

a

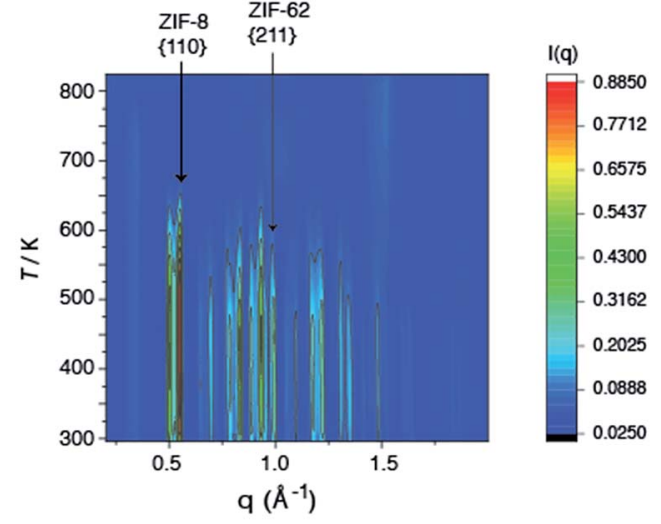

b

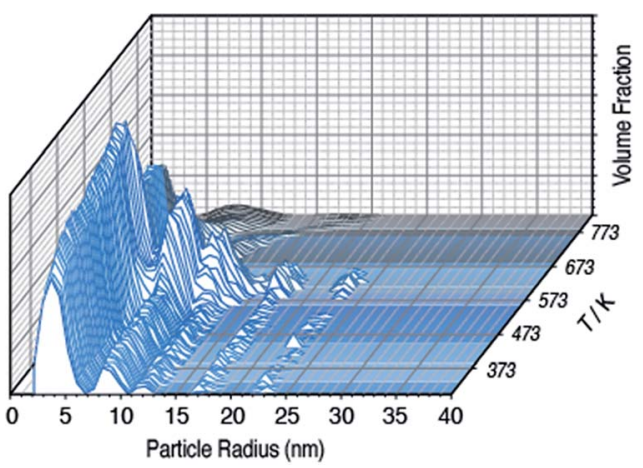

Fig. 3 Temperature resolved diffraction of (a) WAXS profile of (ZIF$8)(\mathrm{ZIF}-62)(20 / 80)$ and (b) volume fraction distributions of (ZIF-8)(ZIF$62)(20 / 80)$ 
3.55, and then starting to rapidly increase at $c a .650 \mathrm{~K}$. At $c a .750$ $\mathrm{K}$, the signal reaches a maximum of $\alpha=4.00$ and starts to decrease rapidly. This data matches the DSC data presented (Fig. $\mathrm{S} 4 \dagger$ ), where a marked increase in heat flow to the sample starts at $c a .650 \mathrm{~K}$, which then reaches a maximum at $c a .750 \mathrm{~K}$.

In a previous experiment, Porod fitting of variable temperature SAXS data taken on a pure sample of ZIF-62 demonstrated $\alpha$ to reach a maximum of 3.9 , at $c a .693 \mathrm{~K}$, i.e. in the liquid state. ${ }^{47}$ The maximum value of $\alpha=4.00$ at $750 \mathrm{~K}$ thus indicates loss of the internal pore structure of ZIF-8 at this temperature. Calculation of the volume weighted fraction of particle sizes below the observable limit of $310 \mathrm{~nm}$ diameter indicates the gradual onset of particle coalescence at ca. $553 \mathrm{~K}$ (Fig. 3b). Scattering from the original particles above $5 \mathrm{~nm}$ in diameter ceases at temperatures approaching $673 \mathrm{~K}$, though the population of $5 \mathrm{~nm}$ diameter particles continues and retains some independence.

Taken together, these data indicate that ZIF-62 amorphizes at $c a .600 \mathrm{~K}$, before beginning to melt at ca. $650 \mathrm{~K}$, i.e. the same temperature region in which the Bragg peaks from ZIF-8 disappear. Thus, the implication here is that the formation of the liquid phase of ZIF-62 is causal to the flux melting of ZIF-8. The apparent offset between $T_{\mathrm{m} \text {,WAxs }}$ and $T_{\mathrm{m} \text {,SAxs }}$ is therefore ascribed to amorphization before melting, which results in the disappearance of Bragg peaks (Fig. 3a). The downturn in the value of $\alpha$ (Fig. S8 $\dagger$ ) is almost identical in temperature to the maximum of the $T_{\mathrm{m}}$ peak in the DSC (Fig. $\mathrm{S} 4 \dagger$ ).

\section{Flux melted glass characterization}

Laboratory Ag-source total scattering experiments were carried out on crystalline ZIF-8, (ZIF-8)(ZIF-62)(20/80), and $\mathrm{a}_{\mathrm{g}}$ [(ZIF$8)_{0.2}$ (ZIF-62 $)_{0.8}$ ] (Fig. 4a, b and S9 $\dagger$ ). The structure factor $S(q)$ for (ZIF-8)(ZIF-62)(20/80) contained Bragg scattering, as expected for this crystalline mixture. On the other hand, consistent with its glassy nature, $a_{\mathrm{g}}\left[(\mathrm{ZIF}-8)_{0.2}(\mathrm{ZIF}-62)_{0.8}\right]$ did not exhibit Bragg diffraction. This observation also indicated that no intact ZIF-8 crystallites remained after the melting of ZIF- 62 . The pair distribution functions, $D(r)$ s, of both (ZIF-8)(ZIF-62)(20/80) and $\mathrm{a}_{\mathrm{g}}\left[(\mathrm{ZIF}-8)_{0.2}(\mathrm{ZIF}-62)_{0.8}\right]$, contain peaks at distances in the range 1.3-6 ̊ that are characteristic of ZIFs. The $\mathrm{Zn}-\mathrm{Zn}$ correlation at ca. $6 \AA$ in the PDFs of both (ZIF-8)(ZIF-62)(20/80) and $\mathrm{a}_{\mathrm{g}}[$ (ZIF$8)_{0.2}$ (ZIF-62 $)_{0.8}$ ] corresponds well with a simple average of the Zn-Zn distances determined from the CIF files of ZIF-8 (6.007 $⿱$ A) and ZIF-62 (5.913 $\mathrm{A}),{ }^{\mathbf{1 2 , 4 9}}$ confirming that the short range order is maintained. The PDF of $a_{g}\left[(Z I F-8)_{0.2}(\text { ZIF-62 })_{0.8}\right]$ shows distinct peaks in the 6.5-8 $\AA$ region, evidencing some correlations in this region. These, through comparison with data collected previously, are ascribed to the ZIF-62 glass and not to remnant ZIF-8 crystallinity (Fig. 4b).

To provide chemical contrast between the two glass components, and enable the use of electron microscopy as a tool for analysing the fate of the ZIF-8 particles postquenching, a second series of samples was prepared using ZIF-67. This framework is the isostructural cobalt(II) analogue of ZIF-8, i.e. $\left[\mathrm{Co}(\mathrm{mIm})_{2}\right]$. The $T_{\mathrm{d}}$ of a pure sample of ZIF-67 was observed at $c a .780 \mathrm{~K}$, which is below that of ZIF- 8 but above the

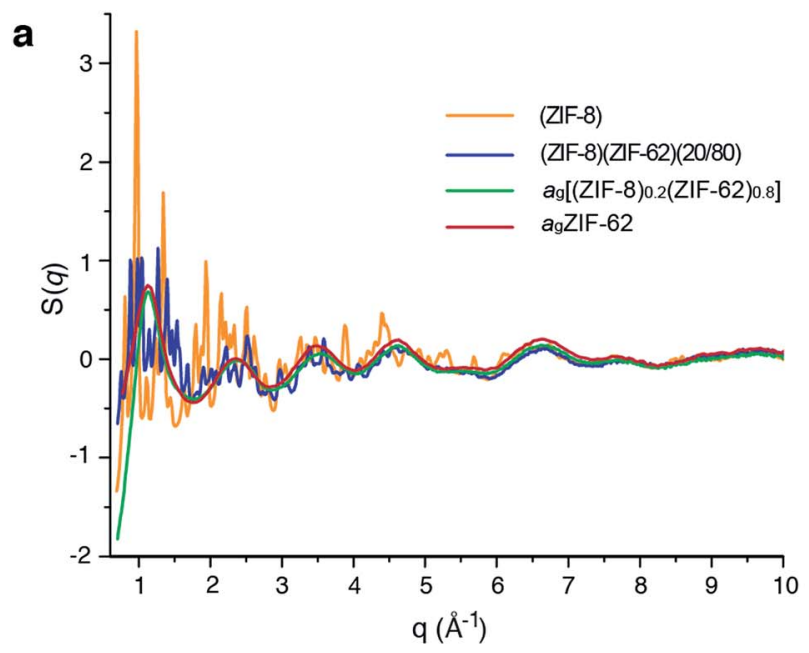

b

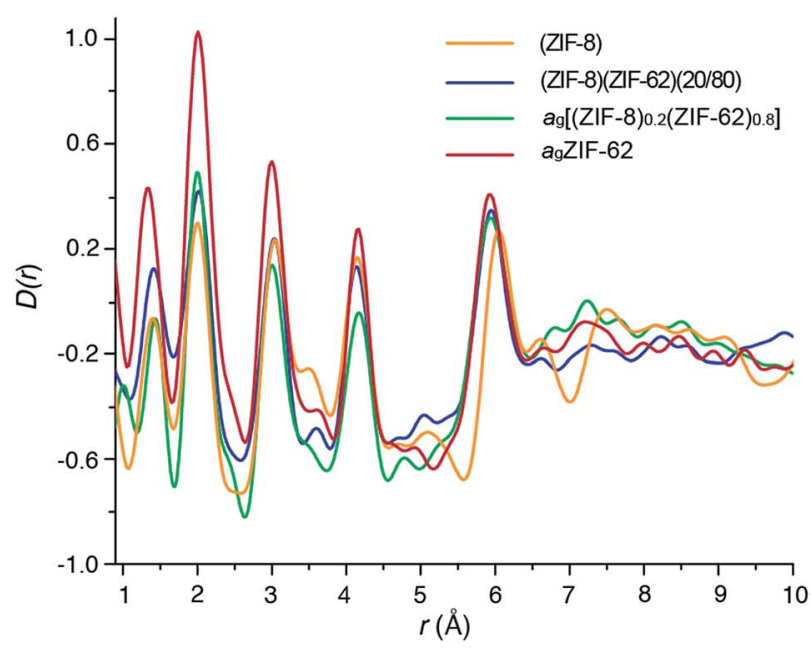

Fig. 4 (a) Structure factors $S(q)$ of (ZIF-8)(ZIF-62)(20/80), $a_{g}[(Z I F-$ $8)_{0.2}(\mathrm{ZIF}-62)_{0.8}$ ] and $\mathrm{ZIF}-8$, alongside that of $\mathrm{a}_{\mathrm{g}} \mathrm{ZIF}-62$ from a previous publication. ${ }^{46}$ (b) Corresponding $X$-ray pair distribution functions $D(r)$.

$T_{\mathrm{m}}$ of ZIF-62 (Fig. S10 and S11 $\dagger$ ). ${ }^{49}$ A sample of (ZIF-67)(ZIF$62)(20 / 80)$ was accordingly prepared by first synthesizing ZIF$67,{ }^{33}$ and following the methodology used for the zinc based mixture. Specifically, $0.1 \mathrm{~g}$ of ZIF-67 was ball-milled for 15 minutes with $0.4 \mathrm{~g}$ ZIF-62. A sample of $\mathrm{a}_{\mathrm{g}}\left[(\mathrm{ZIF}-67)_{0.2}(\mathrm{ZIF}-62)_{0.8}\right]$ was then prepared by heating this mixture to $770 \mathrm{~K}$ in a tube furnace. Annular dark field (ADF) STEM, exhibiting thickness and atomic number contrast, and X-ray energy dispersive spectroscopy (EDS) were then used to provide chemical element maps in both the crystalline mixture and flux melted glass samples. In (ZIF-67)(ZIF-62)(20/80) (Fig. 5a), Zn, C, and $\mathrm{N}$ are observed in one set of particles, while $\mathrm{Co}, \mathrm{C}$ and $\mathrm{N}$ are seen in a different, segregated set of particles.

Investigation of a shard of the flux melted glass, $\mathrm{a}_{\mathrm{g}}[(\mathrm{ZIF}-$ 67) $\left.)_{0.2}(\mathrm{ZIF}-62)_{0.8}\right]$, indicated a much more homogeneous distribution of $\mathrm{Zn}$ and Co (Fig. 5b). The interfaces between the two components in $\left.a_{g}\left[(\text { ZIF-67 })_{0.2} \text { (ZIF-62 }\right)_{0.8}\right]$ were also found to be much more diffuse than in (ZIF-67)(ZIF-62)(20/80), or in samples of (ZIF-67)(ZIF-62)(20/80) heated to ca. $100 \mathrm{~K}$ and $c a$. 
a

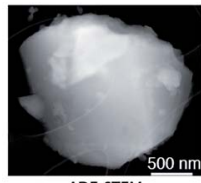
ADF-STEM

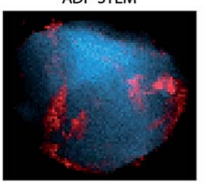

b

Normalized Overlay

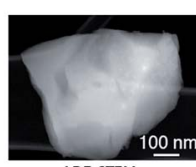
ADF-STEM



Normalized Overlay
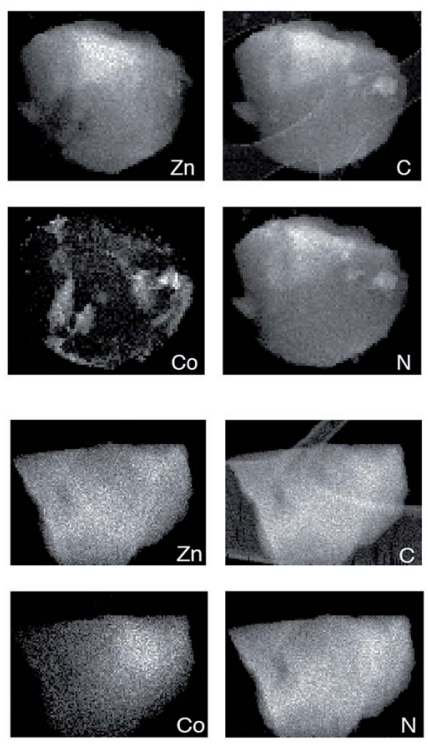

Fig. 5 (a) ADF STEM image, EDS elemental maps for $C, N, Z n$ and Co signals, and Zn (blue) and Co (red) component map overlay of (ZIF67)(ZIF-62)(20/80), (b) ADF STEM image of a shard of $a_{\mathrm{g}}$ [(ZIF67) $0_{0.2}(Z I F-62)_{0.8}$ and corresponding $C, N, Z n$ and Co EDS elemental maps, and an overlay map of $\mathrm{Zn}$ (blue) and $\mathrm{Co}$ (red) components.

$150 \mathrm{~K}$ below $T_{\mathrm{m}}$ (Fig. S12-S14 $\dagger$ ). This was found to be the case across multiple particles, with elemental mapping showing similar sharp interfaces in the crystalline mixture and diffuse interfaces in the glass (Fig S15 and S16 $\dagger$ ). These maps show a two-dimensional representation of a three-dimensional interface, and therefore unambiguous analysis of individual interfaces is limited by signals arising from variation in the thickness of the particle or chemical domains within it and by uncertainty in the orientation of the interface relative to the electron beam. Here, particularly in the Co maps (Fig. 5, S15 and $\mathrm{S} 16 \dagger)$, the preponderance of smooth interfaces observed in $\mathrm{a}_{\mathrm{g}}\left[(\mathrm{ZIF}-67)_{0.2}(\mathrm{ZIF}-62)_{0.8}\right]$ contrasts vividly with the prevalence of abrupt interfaces observed in (ZIF-67)(ZIF-62)(20/80).

The gradual variation of $\mathrm{Zn}$ and $\mathrm{Co}$ in $\mathrm{a}_{\mathrm{g}}\left[(\mathrm{ZIF}-67)_{0.2}\right.$ (ZIF-

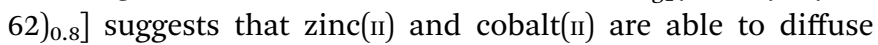
across significant distances in the flux-mediated melt.

\section{Flux melting and porosity}

The permanent porosity of a pure sample of $a_{\mathrm{g}}$ ZIF-62 was recently characterized (Table 1), ${ }^{50}$ with $\mathrm{H}_{2}$ (at $77 \mathrm{~K}$ ) and $\mathrm{CO}_{2}$ (at $273 \mathrm{~K}$ ) uptakes of $9 \mathrm{~mL}$ STP per $\mathrm{g}$ and $20 \mathrm{~mL}$ STP per $\mathrm{g}$ recorded at a pressure of 1 bar. These are lower than for the crystalline ZIF-62 framework (130 mL STP per $\mathrm{g}$ and $39 \mathrm{~mL}$ STP per $\mathrm{g}$ respectively). The uptake of $\mathrm{H}_{2}$ and $\mathrm{CO}_{2}$ by $\mathrm{a}_{\mathrm{g}} \mathrm{ZIF}-62$ is also lower than for $\mathrm{a}_{\mathrm{g}} \mathrm{ZIF}-76-\mathrm{mbIm}$, which displays corresponding $\mathrm{H}_{2}$ and $\mathrm{CO}_{2}$ uptakes of ca. $45 \mathrm{~mL}$ STP per $\mathrm{g}$ and $35 \mathrm{~mL}$ STP per g. ${ }^{51}$ Experiments performed here also demonstrated that ZIF-62 and $\mathrm{a}_{\mathrm{g}}$ ZIF-62 display adsorption behaviour toward $\mathrm{CH}_{4}$ at $273 \mathrm{~K}$ (Fig. S17†).

Our observations indicate that the gas adsorption properties of (ZIF-8)(ZIF-62)(20/80) approximate a weighted average of its two components. The $\mathrm{N}_{2}$ adsorption isotherm of (ZIF-8)(ZIF$62)(20 / 80)$ at $77 \mathrm{~K}$ displays type I nitrogen behaviour, from which an accessible surface area of $350 \mathrm{~m}^{2} \mathrm{~g}^{-1}$ was calculated using the BET model. As the adsorbate pressure approached 1 bar, the $\mathrm{N}_{2}$ uptake at $77 \mathrm{~K}$ plateaus around $90 \mathrm{~mL}$ STP per $\mathrm{g}$ (Fig. 6a). This is consistent with the reported experimental value for $\mathrm{N}_{2}$ uptake in ZIF-8 of $c a$. $400 \mathrm{~mL}$ STP per $\mathrm{g},{ }^{12}$ and our own measurements on the material (Fig. S18 $\dagger$ ). It is in broad agreement with the $20 \%$ quantity of ZIF-8 in (ZIF-8)(ZIF-62)(20/80).

For $\mathrm{H}_{2}$ at $77 \mathrm{~K}$, (ZIF-8)(ZIF-62)(20/80) takes up $105 \mathrm{~mL}$ STP per $\mathrm{g}$ which is slightly lower than both pure ZIF-62 (130 mL STP per g) and ZIF-8 (145 mL STP per g) ${ }^{12}$ (Fig. 6b, Table 1). This indicates that the ball milling process used to produce (ZIF8)(ZIF-62)(20/80) may close off a number of small pores, which are accessible to $\mathrm{H}_{2}$ but not larger molecules such as $\mathrm{N}_{2}$. (ZIF-8)(ZIF-62)(20/80) reversibly adsorbs $\mathrm{CO}_{2}$ at $273 \mathrm{~K}$ (Fig. 7a). An uptake capacity of $31 \mathrm{~mL}$ STP per $\mathrm{g}$ was observed at a pressure of 1 bar, which equates to $5.7 \mathrm{wt} \%$. This uptake is only slightly lower than that of ZIF-62 (39 mL STP per g), ${ }^{50}$ and ZIF-8 (53 mL STP per $\mathrm{g}$ ). ${ }^{52}$

A considerable degree of accessible porosity was found for $\mathrm{a}_{\mathrm{g}}\left[(\mathrm{ZIF}-8)_{0.2}(\mathrm{ZIF}-62)_{0.8}\right]$, i.e. upon flux melting and quenching of (ZIF-8)(ZIF-62)(20/80). This glass took up $19 \mathrm{~mL} \mathrm{STP} \mathrm{per} \mathrm{g}$ of $\mathrm{CO}_{2}$ at 1 bar (Fig. 7a), which equates to $3.6 \mathrm{wt} \%$. The desorption isotherm mapped back exactly on the adsorption isotherm, indicating the absence of significant barriers to gas diffusion. Further adsorption experiments using $\mathrm{O}_{2}$ and $\mathrm{CH}_{4}$ were also performed, which indicate that $\mathrm{a}_{\mathrm{g}}\left[(\mathrm{ZIF}-8)_{0.2}(\mathrm{ZIF}-62)_{0.8}\right]$ is

Table 1 Gas adsorption properties ( $\mathrm{mL}$ STP per $\mathrm{g}$ ) for the crystalline and glass samples at 1 bar

\begin{tabular}{|c|c|c|c|c|c|}
\hline Gas (kinetic diameter/Å), temperature/K & $\mathrm{H}_{2}(2.9), 77$ & $\mathrm{CO}_{2}(3.3), 273$ & $\mathrm{O}_{2}(3.46), 273$ & $\mathrm{~N}_{2}(3.64), 77$ & $\mathrm{CH}_{4}(3.76), 273$ \\
\hline ZIF-62 & $130^{a}$ & $39^{a}$ & $0^{a}$ & $0^{a}$ & 27 \\
\hline Simulated & 130.5 & 33.9 & 5.2 & 174.2 & 18.6 \\
\hline$a_{g} Z I F-62$ & $9.3^{a}$ & $20.1^{a}$ & $1.5^{a}$ & $0^{a}$ & 3.9 \\
\hline Simulated & 40.5 & 7.8 & 0.7 & 45.9 & 1.4 \\
\hline$(\mathrm{ZIF}-8)(\mathrm{ZIF}-62)(20 / 80)$ & 104.5 & 30.7 & 4.4 & 104.3 & 15.2 \\
\hline Simulated & 119.9 & 29.5 & 4.4 & 207.2 & 16.1 \\
\hline $\mathrm{a}_{\mathrm{g}}\left[(\mathrm{ZIF}-8)_{0.2}(\mathrm{ZIF}-62)_{0.8}\right]$ & 27.8 & 18.7 & 1.6 & 1.1 & 4.7 \\
\hline Simulated & 48.5 & 9.1 & 1.3 & 105.9 & 2.7 \\
\hline
\end{tabular}

${ }^{a}$ Denotes data taken from ref. 50 . 
a

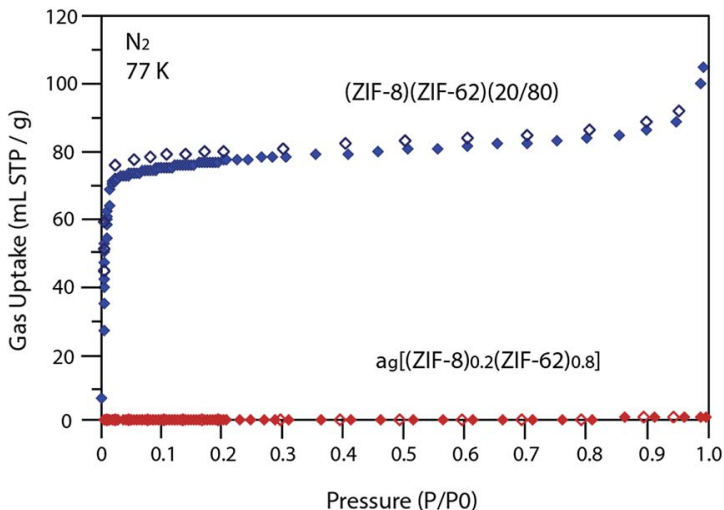

b

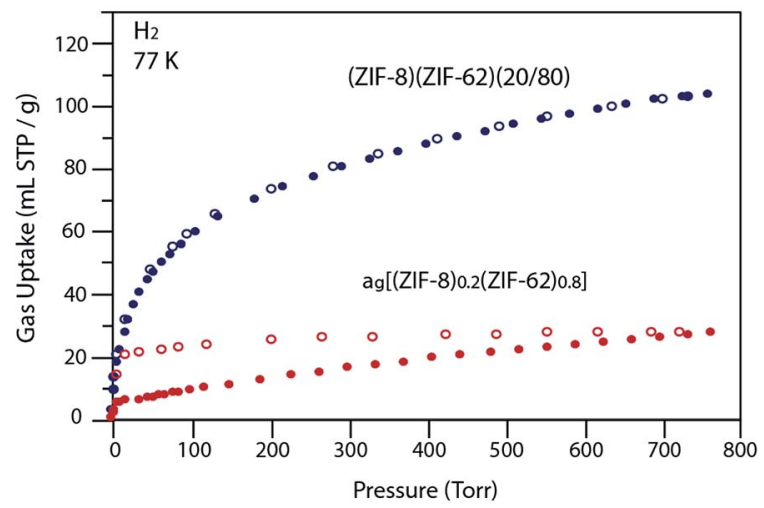

Fig. 6 (a) $\mathrm{N}_{2}$ at $77 \mathrm{~K}$ and (b) $\mathrm{H}_{2}$ at $77 \mathrm{~K}$ gas isotherms for the zinc-based crystalline mixtures and glasses. Closed symbols represent adsorption isotherms and open symbols represent desorption isotherms.

permanently accessible to these guest molecules (Fig. $7 \mathrm{~b})$. The observed porosity of (ZIF-8)(ZIF-62)(20/80) towards $\mathrm{N}_{2}$ at $77 \mathrm{~K}$ is virtually eliminated by the vitrification process, however (Fig. 6a). The pore network of the ZIF-8 component, which is accessible in (ZIF-8)(ZIF-62)(20/80), appears to collapse in $\mathrm{a}_{\mathrm{g}}\left[(\mathrm{ZIF}-8)_{0.2}(\mathrm{ZIF}-62)_{0.8}\right]$ and places kinetic barriers to diffusion at low temperatures. This is also evident for adsorbate molecules as small as $\mathrm{H}_{2}$ (Fig. 6b). Here, the small amount of $\mathrm{H}_{2}$ uptake into $\mathrm{a}_{\mathrm{g}}\left[(\mathrm{ZIF}-8)_{0.2}(\mathrm{ZIF}-62)_{0.8}\right]$ confirms that it is accessible to incoming guest molecules. However, considerable hysteresis is evident in the desorption branch of this isotherm. This produced an isotherm that does not reach equilibrium between the adsorbed and free gas under any practical measurement regime.

Analysis of the $\mathrm{CO}_{2}$ isotherms at $273 \mathrm{~K}$ yielded surface areas of $325 \mathrm{~m}^{2} \mathrm{~g}^{-1}$ and $202 \mathrm{~m}^{2} \mathrm{~g}^{-1}$ for (ZIF-8)(ZIF-62)(20/80) and $\mathrm{a}_{\mathrm{g}}$ (ZIF$\left.8)_{0.2}(\text { ZIF-62 })_{0.8}\right]$, respectively. Pore size distributions were also calculated from these isotherms (Fig. S19 and S20 $\dagger$ ), which indicates the major pores in both materials have diameters of around $5 \AA$, while a smaller number of cavities have diameters centered on $9 \AA$. The pore volumes accessible to $\mathrm{CO}_{2}$ were 0.095 $\mathrm{cm}^{3} \mathrm{~g}^{-1}$ and $0.068 \mathrm{~cm}^{3} \mathrm{~g}^{-1}$, respectively.

Gas adsorption isotherms were also measured on (ZIF67)(ZIF-62)(20/80) and $\left.a_{g}\left[(\text { ZIF-67) })_{0.2} \text { (ZIF-62) }\right)_{0.8}\right]$ (Fig. S21, Table $\mathrm{S} 1 \dagger)$. As anticipated, the crystalline material adsorbs $\mathrm{N}_{2}$ at $77 \mathrm{~K}$ but not after vitrification. $\mathrm{H}_{2}$ is taken up at $77 \mathrm{~K}$, but with

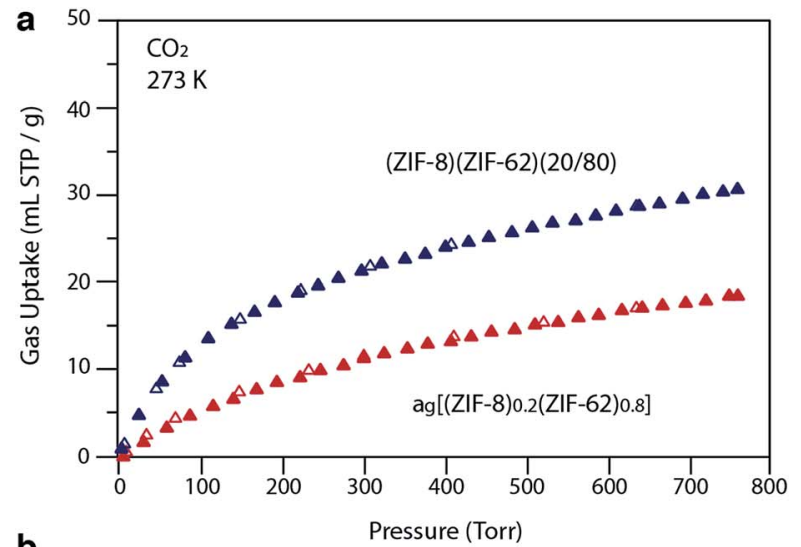

b

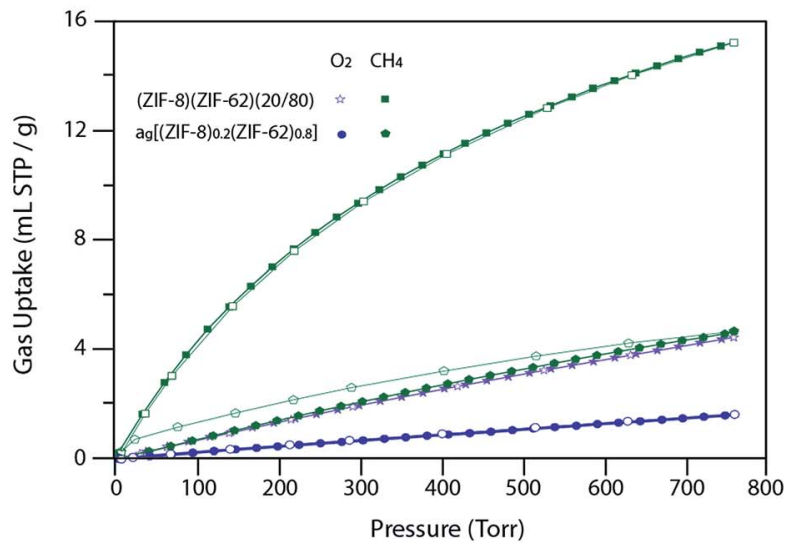

Fig. 7 (a) $\mathrm{CO}_{2}$ isotherm at $273 \mathrm{~K}$ and (b) $\mathrm{O}_{2}$ and $\mathrm{CH}_{4}$ at $273 \mathrm{~K}$ isotherms for zinc based samples. Closed symbols represent adsorption isotherms and open symbols represent desorption isotherms.

hysteresis. On the other hand, $\mathrm{CO}_{2}$ adsorption at $273 \mathrm{~K}$ is largely preserved when the crystalline material is transformed to the glass. Surface areas of $218 \mathrm{~m}^{2} \mathrm{~g}^{-1}$ for (ZIF-67)(ZIF-62)(20/80) and $194 \mathrm{~m}^{2} \mathrm{~g}^{-1}$ for $\left.\mathrm{a}_{\mathrm{g}}\left[(\mathrm{ZIF}-67)_{0.2} \text { (ZIF-62 }\right)_{0.8}\right]$ were estimated from these isotherms together with accessible pore volumes of $0.067 \mathrm{~cm}^{3} \mathrm{~g}^{-1}$ and $0.062 \mathrm{~cm}^{3} \mathrm{~g}^{-1}$, respectively. Estimated pore size distributions (Fig. S22 and S23 $\dagger$ ) paralleled their zinc counterparts. The rate of uptake of $\mathrm{CO}_{2}$ in these materials was measured. A comparison of these kinetics plots (Fig. S24†) reveals that the diffusion of $\mathrm{CO}_{2}$ in the glass is slower than in its crystalline precursor, which is consistent with its more constricted and tortuous pore network.

To provide further information on the pores present in the samples before and after vitrification, positron annihilation lifetime spectroscopy (PALS) experiments were carried out (Fig. S25 and S26, Table S2 $\dagger$ ). Measurements on crystalline ZIF-8 indicated one main cavity size of $9.5 \AA$ diameter, which is close to the reported $11.6 \AA$ value after accounting for van der Waals radii. A minor cavity of $23 \AA$ was also observed in the study. (ZIF-8)(ZIF-62)(20/80) was also found to possess a major cavity with 5.8 A diameter, alongside a secondary cavity with a diameter of $10 \AA$. This is consistent with the presence of a major cavity in pure ZIF-8 at $9.5 \AA$, and one in ZIF-4, which is closely related to ZIF-62, at $6.2 \AA \AA^{44}$ PALS measurements on $\mathrm{a}_{\mathrm{g}}[$ (ZIF$\left.\left.8)_{0.2(\text { ZIF-62) }}\right)_{0.8}\right]$ also show a bimodal distribution, with a similar 
cavity size distribution to a pure sample of agZIF-62, found previously (Fig. S25, Table S2 $\dagger$ ). ${ }^{25}$ The key difference between the two samples is that the smaller pore limiting aperture is larger for the $\left.\mathrm{a}_{\mathrm{g}}\left[(\mathrm{ZIF}-8)_{0.2} \text { (ZIF-62 }\right)_{0.8}\right]$ glass at $3.1 \AA$ compared to $2.5 \AA$ for $\mathrm{a}_{\mathrm{g}}(\mathrm{ZIF}-62)$. In all cases, these results are broadly consistent with the pore size distributions obtained from $\mathrm{CO}_{2}$ sorption analysis.

Grand canonical Monte Carlo (GCMC) simulations of gas adsorption by (ZIF-8)(ZIF-62)(20/80), for which structural models of each of the crystalline phases were derived from single-crystal X-ray diffraction, led to broad agreement between calculated and experimental data (Table 1). For example, $\mathrm{CO}_{2}$ uptake at $273 \mathrm{~K}$ in (ZIF-8)(ZIF-62)(20/80) was predicted as $30 \mathrm{~mL}$ STP per $\mathrm{g}$, which is very close to the experimental $\mathrm{CO}_{2}$ measurement ( $31 \mathrm{~mL}$ STP per g). Similarly, the simulated $\mathrm{CH}_{4}$ uptake at $273 \mathrm{~K}$ of $16 \mathrm{~mL}$ STP per g agrees well with the experimental value of $15 \mathrm{~mL}$ STP per g. Simulations overestimated $\mathrm{N}_{2}$ adsorption at low temperature $(77 \mathrm{~K})$ in (ZIF-8)(ZIF-62)(20/80), where diffusion limitations prevented the ingress of the adsorbate in experimental isotherms. The source of error was proven by simulating $\mathrm{N}_{2}$ uptake in (ZIF8)(ZIF-62)(20/80) at $195 \mathrm{~K}$ (25 mL STP per g), which agreed well with an observed experimental value at $195 \mathrm{~K}$ of $23 \mathrm{~mL}$ STP per $\mathrm{g}$ (ESI Table S5†).

The modelling of amorphous structures is extremely challenging due to the complexity of constructing accurate models. To provide a qualitative estimate of the gas sorption behaviour of $\mathrm{a}_{\mathrm{g}}\left[(\mathrm{ZIF}-8)_{0.2}(\mathrm{ZIF}-62)_{0.8}\right]$, we followed existing literature ${ }^{20,53}$ and used a molecular dynamics (MD) method to develop a model for $a_{g}$ ZIF-62. Initial configurations of ZIF-62 were melted in the NPT ensemble at 1 bar by heating to $1500 \mathrm{~K}$ at a rate of $100 \mathrm{~K} \mathrm{ps}^{-1}$ from $300 \mathrm{~K}$ before quenching to $300 \mathrm{~K}$ at a controlled rate. Calculations of the gas adsorption behaviour of this model were then combined with those using a crystalline model of ZIF-8 (ESI $\dagger$ ). Simulated $\mathrm{O}_{2}$ uptake $(1 \mathrm{~mL}$ STP per g) at $273 \mathrm{~K}$ was in agreement with negligible experimental uptake of $2 \mathrm{~mL}$ STP per $\mathrm{g}$ for $\mathrm{a}_{\mathrm{g}}\left[(\mathrm{ZIF}-8)_{0.2}(\mathrm{ZIF}-62)_{0.8}\right]$, whilst the low predictions for $\mathrm{CH}_{4}$ adsorption at $273 \mathrm{~K}$, agreed broadly with experimental data. Simulations overestimated $\mathrm{N}_{2}$ adsorption at low temperature $(77 \mathrm{~K})$ in $\mathrm{a}_{\mathrm{g}}\left[(\mathrm{ZIF}-8)_{0.2}(\mathrm{ZIF}-62)_{0.8}\right]$, though the simulated $\mathrm{N}_{2}$ uptake in $\mathrm{a}_{\mathrm{g}}\left[(\mathrm{ZIF}-8)_{0.2}(\mathrm{ZIF}-62)_{0.8}\right]$ at $273 \mathrm{~K}$ of $1 \mathrm{~mL}$ STP per $\mathrm{g}$ agrees well with the experimental value of $1 \mathrm{~mL}$ STP per g (ESI Table S5 $\dagger$ ). The over prediction of $\mathrm{H}_{2}$ uptake at $77 \mathrm{~K}$ ( $49 \mathrm{~mL}$ STP per g) compared to the experimental value ( $28 \mathrm{~mL}$ STP per $\mathrm{g}$ ) is consistent with our assertion that the ZIF-8 structure does not remain intact within the flux melted glass (Table 1). Full details of molecular simulations are given in the ESI, $\dagger$ though two different configurations (imidazolate and benzimidazolate linkers with partial occupancies of $62.5 \%$ and $37.5 \%$, respectively) of ZIF-62 were considered in molecular simulations due to the disorder in the framework. The average of the predictions agreed well with the experimental data (Table 1). Secondly, our computational approach represents the first instance where accurate predictions for the gas adsorption performances of ZIF-ZIF crystalline mixture absorbents and ZIF-ZIF glassy flux melts have been made.

\section{Conclusions}

These results show that the concept of flux melting, that is, the use of a molten salt as a solvent, may be applicable to MOF chemistry. The flux melted glass reported here is different from the intriguing mixed matrix membrane created by Kertik et al., by thermally amorphizing a ZIF-8 loaded imide polymer. ${ }^{19}$ This in situ amorphization, by heating the MMM at $623 \mathrm{~K}$ for up to 24 hours, was observed to cross-link ZIF-8 particles with the imide. This resulted in retention of the porous interior of the ZIF-8 component, though in an amorphous material. Here, the highly porous ZIF-8 interior does not appear to be retained, suggesting a different process to the cross-linking in the thermally treated MMM.

From a fundamental view, the successful realisation of flux melting, which uses the liquid state of ZIF-62 to facilitate the melting of ZIF-8, presents a method by which the $T_{\mathrm{m}}$ of a nonmelting framework can be accessed. Use of elemental contrast in the electron microscopy experiments shows that melting of the cobalt analogue of ZIF- 8 occurs quickly upon formation of the liquid ZIF-62, and results in regions of the glass which contain higher concentrations of the cobalt-containing component than others. The flux melted glass contains short range ordering reminiscent of the crystalline ZIF-62 parent phase, and a continuous random network akin to that of amorphous $\mathrm{SiO}_{2}$, though with accessible porosity. The increased porosity relative to the pure ZIF-62 glass is ascribed to the ZIF-8 component disrupting the close packing of the ZIF-62 matrix in the liquid phase, rather than any retention of the nanopores belonging to crystalline ZIF-8. The demonstration of porosity towards $\mathrm{H}_{2}$ and $\mathrm{CO}_{2}$, in the flux melted samples is notable, and suggests possibilities in, for example, free-standing membrane manufacture.

\section{Conflicts of interest}

There are no conflicts to declare.

\section{Acknowledgements}

TDB would like to thank the Royal Society for a University Research Fellowship (UF150021), and EPSRC (grant EP/ R015481/1). LL acknowledges an EPSRC studentship. JH would like to acknowledge funding from the EPSRC (EP/ R015481/1). We acknowledge the provision of synchrotron access to beamline I22 (NT18236-1) at the Diamond Light Source, Rutherford Appleton Laboratory UK. SL acknowledges the China Scholarship Council (CSC). This work benefited from the use of the SasView application, originally developed under NSF Award DMR-0520547. SasView also contains code developed with funding from the EU Horizon 2020 programme under the SINE2020 project Grant No. 654000. S. M. Collins acknowledges the Henslow Research Fellowship and Girton College, Cambridge. S. M. Collins and PAM acknowledge funding from the European Research Council under the European Union's Seventh Framework Program (No. FP7/20072013)/ERC Grant Agreement No. 291522-3DIMAGE, and from 
the EPSRC (EP/R008779/1). We are grateful to Christopher Ashling for assistance with PDF measurements. SMC and XY were supported by the NSF, Division of Chemistry, under award number CHE-1661655. CMD acknowledges support from the Australian Research Council Discovery Early Career Researcher Award (DE140101359) and the Veski Inspiring Women Fellowship.

\section{Notes and references}

1 H. Furukawa, K. E. Cordova, M. O'Keeffe and O. M. Yaghi, Science, 2013, 341, 974-986.

2 J. W. Yoon, H. Chang, S. J. Lee, Y. K. Hwang, D. Y. Hong, S. K. Lee, J. S. Lee, S. Jang, T. U. Yoon, K. Kwac, Y. Jung, R. S. Pillai, F. Faucher, A. Vimont, M. Daturi, G. Ferey, C. Serre, G. Maurin, Y. S. Bae and J. S. Chang, Nat. Mater., 2017, 16, 526-531.

3 T. M. McDonald, J. A. Mason, X. Q. Kong, E. D. Bloch, D. Gygi, A. Dani, V. Crocella, F. Giordanino, S. O. Odoh, W. S. Drisdell, B. Vlaisavljevich, A. L. Dzubak, R. Poloni, S. K. Schnell, N. Planas, K. Lee, T. Pascal, L. W. F. Wan, D. Prendergast, J. B. Neaton, B. Smit, J. B. Kortright, L. Gagliardi, S. Bordiga, J. A. Reimer and J. R. Long, Nature, 2015, 519, 303-308.

4 A. Schneermann, V. Bon, I. Schwedler, I. Senkoska, S. Kaskel and R. Fischer, Chem. Soc. Rev., 2014, 43, 60626096.

5 S. Krause, V. Bon, I. Senkoska, U. Stoeck, D. Wallacher, D. M. Többens, S. Zander, R. S. Pillai, G. Maurin, F. X. Coudert and S. Kaskel, Nature, 2016, 532, 348-352.

6 S. Dissegna, K. Epp, W. R. Heinz, G. Kieslich and R. A. Fischer, Adv. Mater., 2018, 30, 1704501.

7 S. Furukawa, J. Reboul, S. Diring, K. Sumida and S. Kitagawa, Chem. Soc. Rev., 2014, 43, 5700-5734.

8 M. S. Denny, J. C. Moreton, L. Benz and S. M. Cohen, Nat. Rev. Mater., 2016, 1, 16078.

9 B. Bueken, N. Van Velthoven, T. Willhammar, T. Stassin, I. Stassen, D. A. Keen, G. V. Baron, J. F. M. Denayer, R. Ameloot, S. Bals, D. De Vos and T. D. Bennett, Chem. Sci., 2017, 8, 3939-3948.

10 O. Shekhah, J. Liu, R. A. Fischer and C. Woll, Chem. Soc. Rev., 2011, 40, 1081-1106.

11 J. C. Tan and A. K. Cheetham, Chem. Soc. Rev., 2011, 40, 1059-1080.

12 K. S. Park, Z. Ni, A. P. Cote, J. Y. Choi, R. D. Huang, F. J. Uribe-Romo, H. K. Chae, M. O'Keeffe and O. M. Yaghi, Proc. Natl. Acad. Sci. U. S. A., 2006, 103, 10186-10191.

13 Y. Q. Tian, Y. M. Zhao, Z. X. Chen, G. N. Zhang, L. H. Weng and D. Y. Zhao, Chem.-Eur. J., 2007, 13, 4146-4154.

14 I. Stassen, M. Styles, G. Grenci, H. Van Gorp, W. Vanderlinden, S. De Feyter, P. Falcaro, D. De Vos, P. Vereecken and R. Ameloot, Nat. Mater., 2016, 15, 304-310.

15 T. Wu, X. Feng, S. K. Elsaidi, P. K. Thallapally and M. A. Carreon, Ind. Eng. Chem. Res., 2017, 56, 1682-1686.

16 H. C. Zhang, J. Hou, Y. X. Hu, P. Y. Wang, R. W. Ou, L. Jiang, J. Z. Liu, B. D. Freeman, A. J. Hill and H. T. Wang, Sci. Adv., 2018, 4, eaaq0066.
17 B. Seoane, J. Coronas, I. Gascon, M. E. Benavides, O. Karvan, J. Caro, F. Kapteijn and J. Gascon, Chem. Soc. Rev., 2015, 44, 2421-2454.

18 S. W. Yu, S. C. Li, S. L. Huang, Z. H. Zeng, S. Cui and Y. Liu, J. Membr. Sci., 2017, 540, 155-164.

19 A. Kertik, L. H. Wee, M. Pfannmoller, S. Bals, J. A. Martens and I. F. J. Vankelecom, Energy Environ. Sci., 2017, 10, 2342-2351.

20 R. Gaillac, P. Pullumbi, K. A. Beyer, K. W. Chapman, D. A. Keen, T. D. Bennett and F. X. Coudert, Nat. Mater., 2017, 16, 1149-1154.

21 J. B. James and Y. S. Lin, J. Phys. Chem. C, 2016, 120, 1401514026.

22 T. D. Bennett and S. Horike, Nat. Rev. Mater., 2018, 3, 431440.

23 S. S. Nagarkar, S. Horike, T. Itakura, B. Le Ouay, A. Demessence, M. Tsujimoto and S. Kitagawa, Angew. Chem., Int. Ed., 2017, 56, 4976-4981.

24 D. Umeyama, S. Horike, M. Inukai, T. Itakura and S. Kitagawa, J. Am. Chem. Soc., 2015, 137, 864-870.

25 A. Qiao, T. D. Bennett, H. T. Tao, A. Krajnc, G. Mali, C. M. Doherty, A. W. Thornton, J. C. Mauro, G. N. Greaves and Y. Z. Yue, Sci. Adv., 2018, 4, eaao6827.

26 F. A. Lindemann, Phys. Z., 1910, 11, 609.

27 T. D. Bennett, J. C. Tan, Y. Z. Yue, E. Baxter, C. D. Ducati, N. Terril, H. Y. Yeung, Z. Zhou, W. Chen, S. Henke, A. K. Cheetham and G. N. Greaves, Nat. Commun., 2015, 6, 8079.

28 J. E. Shelby, Introduction to Glass Science and Technology, Royal Society of Chemistry, 2nd edn, 2005.

29 H. W. Kui, A. L. Greer and D. Turnbull, Appl. Phys. Lett., 1984, 45, 615-616.

30 R. D. Rogers and K. R. Seddon, Science, 2003, 302, 792-793. 31 J. S. Wilkes, Green Chem., 2002, 4, 73-80.

32 M. Gustafsson and X. D. Zou, J. Porous Mater., 2013, 20, 5563.

33 Q. Shi, Z. F. Chen, Z. W. Song, J. P. Li and J. X. Dong, Angew. Chem., Int. Ed., 2011, 50, 672-675.

34 M. Basham, J. Filik, M. T. Wharmby, P. C. Chang, B. El Kassaby, M. Gerring, J. Aishima, K. Levik, B. C. Pulford, I. Sikharulidze, D. Sneddon, M. Webber, S. S. Dhesi, F. Maccherozzi, O. Svensson, S. Brockhauser, G. Naray and A. W. Ashton, J. Synchrotron Radiat., 2015, 22, 853-858.

35 J. Filik, A. W. Ashton, P. C. Y. Chang, P. A. Chater, S. J. Day, M. Drakopoulos, M. W. Gerring, M. L. Hart, O. V. Magdysyuk, S. Michalik, A. Smith, C. C. Tang, N. J. Terrill, M. T. Wharmby and H. Wilhelm, J. Appl. Crystallogr., 2017, 50, 959-966.

36 B. R. Pauw, A. J. Smith, T. Snow, N. J. Terrill and A. F. Thünemann, J. Appl. Crystallogr., 2017, 50, 1800-1811. 37 M. e. a. Doucet, SASView 4.1.1, 2017.

38 B. R. Pauw, J. S. Pedersen, S. Tardif, M. Takata and B. B. Iversen, J. Appl. Crystallogr., 2013, 46, 365-371.

39 I. Bressler, B. R. Pauw and A. F. Thünemann, J. Appl. Crystallogr., 2015, 48, 962-969.

40 A. K. Soper, Tech. Rep. RAL-TR-2011-013, 2011. 
41 A. K. Soper and E. R. Barney, J. Appl. Crystallogr., 2011, 44, 714-726.

42 F. De la Pēna, T. Ostasevicius, V. T. Fauske, P. Burdet, P. Jokubauskas and M. Sarahan, hyperspy/hyperspy: HyperSpy 1.3, 2016.

43 S. J. Tao, J. Chem. Phys., 1972, 56, 5499.

44 A. W. Thornton, K. E. Jelfs, K. Konstas, C. Doherty, A. J. Hill, A. K. Cheetham and T. D. Bennett, Chem. Commun., 2016, 52, 3750-3753.

45 K. S. Walton and R. Q. Snurr, J. Am. Chem. Soc., 2007, 129, 8552-8556.

46 T. D. Bennett, Y. Z. Yue, P. Li, A. Qiao, H. Tao, G. N. Greaves, T. Richards, G. I. Lampronti, S. A. T. Redfern, F. Blanc, O. K. Farha, J. T. Hupp, A. K. Cheetham and D. A. Keen, J. Am. Chem. Soc., 2016, 138, 3484-3492.

47 L. Longley, S. M. Collins, C. Zhou, G. J. Smales, S. E. Norman, N. J. Brownbill, C. W. Ashling, P. Chater, R. Tovey, C. B. Schönlieb, T. F. Headen, N. J. Terrill, Y. Z. Yue, A. J. Smith, F. Blanc, D. A. Keen, P. A. Midgley and T. D. Bennett, Nat. Commun., 2018, 9, 2135.
48 M. G. Goesten, E. Stavitski, J. Juan-Alcaniz, A. MartinezJoaristi, A. V. Petukhov, F. Kapteijn and J. Gascon, Catal. Today, 2013, 205, 120-127.

49 R. Banerjee, A. Phan, B. Wang, C. Knobler, H. Furukawa, M. O'Keeffe and O. M. Yaghi, Science, 2008, 319, 939-943.

50 R. N. Widmer, G. I. Lampronti, S. Anzellini, R. Gaillac, S. Farsang, C. Zhou, A. Belenguer, H. Palmer, A. K. Kleppe, M. T. Wharmby, S. A. T. R. Redfern, F. X. Coudert, S. G. Macleod and T. D. Bennett, ChemRxiv, 2018, DOI: 10.26434/chemrxiv.6541190.v6541193.

51 C. Zhou, L. Longley, A. Krajnc, G. J. Smales, A. Qiao, I. Eruçar, C. M. Doherty, A. W. Thornton, A. J. Hill, C. W. Ashling, O. T. Qasvini, S. J. Lee, P. Chater, N. J. Terrill, A. J. Smith, Y. Z. Yue, G. Mali, D. A. Keen, S. G. Telfer and T. D. Bennett, Nat. Commun., 2018, 9, 5042. 52 S. S. Mondal, M. Hovestadt, S. Dey, C. Paula, S. Glomb, A. Kelling, U. Schilde, C. Janiak, M. Hartmann and H. J. Holdt, CrystEngComm, 2017, 19, 5882-5891.

53 C. D. Williams, K. P. Travis, N. A. Burton and J. H. Harding, Microporous Mesoporous Mater., 2016, 228, 215-223. 